\title{
Vascular Medicine
}

http://vmj.sagepub.com

\section{A prognostic model for amputation in critical lower limb ischemia}

HM Klomp, EW Steyerberg, CHA Wittens, H van Urk, JDF Habbema and For the ESES study group Vasc Med 2009; 14; 109

DOI: $10.1177 / 1358863 \times 08098227$

The online version of this article can be found at:

http://vmj.sagepub.com/cgi/content/abstract/14/2/109

\section{Published by:}

(3)SAGE

http://www.sagepublications.com

Additional services and information for Vascular Medicine can be found at:

Email Alerts: http://vmj.sagepub.com/cgi/alerts

Subscriptions: http://vmj.sagepub.com/subscriptions

Reprints: http://www.sagepub.com/journalsReprints.nav

Permissions: http://www.sagepub.co.uk/journalsPermissions.nav

Citations http://vmj.sagepub.com/cgi/content/refs/14/2/109 


\title{
A prognostic model for amputation in critical lower limb ischemia
}

HM Klomp Department of Public Health, Center for Clinical Decision Sciences, Erasmus MC and; Vascular Unit, Department of General Surgery, Erasmus MC - University Medical Center Rotterdam, EW Steyerberg Department of Public Health, Center for Clinical Decision Sciences, Erasmus MC, CHA Wittens Vascular Unit, Department of General Surgery, Erasmus MC - University Medical Center Rotterdam, H van Urk Vascular Unit, Department of General Surgery, Erasmus MC - University Medical Center Rotterdam, JDF Habbema Department of Public Health, Center for Clinical Decision Sciences, Erasmus MC and For the ESES study group

\begin{abstract}
In a (negative) multicenter randomized trial on management for inoperable critical lower limb ischemia, comparing spinal cord stimulation and best medical treatment, a number of pre-defined factors were analyzed for prognostic value. We included a radiological arterial disease score, modified from the SVS/ISCVS runoff score. The purpose of this analysis was to evaluate clinical factors and commonly used circulatory measurements for prognostic modeling in patients with critical lower limb ischemia. We determined the incidence of amputation and its relation to various pre-defined risk factors. A total of 120 patients with critical limb ischemia were included in the study. The integrity of circulation in the affected limb was evaluated on five levels: suprainguinal, infrainguinal, popliteal, infrapopliteal and pedal. A total radiological arterial disease score was calculated from 1 (full integrity of circulation) to 20 (maximally compromised state). We used Cox regression analysis to quantify prognostic effects and differential treatment (predictive) effects. Major amputation occurred in $33 \%$ of the patients at 6 months and in $51 \%$ at 2 years. The presence of ischemic skin lesions and the radiological arterial disease score were independent prognostic factors for amputation. Patients with ulcerations or gangrene had a higher amputation risk (hazard ratio $2.38, p=0.018$ and $2.30, p=0.036$ respectively) as well as patients with a higher radiological arterial disease score (hazard ratio 1.17 per increment, $p=0.003$ ). We did not observe significant interactions between prognostic factors and the effect of spinal cord stimulation. In conclusion, in patients with critical lower limb ischemia, the presence of ischemic skin lesions and the described radiological arterial disease score can be used to estimate amputation risk.
\end{abstract}

Keywords: amputation; peripheral arterial disease; predictive value of tests; prognosis; randomized controlled trials

\section{Introduction}

The fate of patients with critical limb ischemia (CLI) is influenced by treatment as well as by a number of other variables. ${ }^{1-3}$ Prospective studies provide an excellent basis to identify risk factors for amputation. In the modern practice of vascular surgery, it is difficult to study the natural history of CLI. Older studies in patients with CLI not undergoing revascularization showed that major amputation of the limb is necessary in a majority of patients within a year. ${ }^{4-8}$ However, Marston et al. ${ }^{9}$ showed

Correspondence to: Ms HM Klomp, Netherlands Cancer Institute/Antoni van Leeuwenhoek Hospital, Plesmanlaan 121, NL - 1066 CX Amsterdam, The Netherlands.

E-mail: h.klomp@nki.nl that limb salvage can be achieved in most patients with arterial insufficiency and uncomplicated chronic non-healing limb ulcers when treated in a dedicated wound program.

Several authors have recommended the use of spinal cord stimulation (SCS) for patients with CLI in whom a meaningful vascular reconstruction is not possible. ${ }^{10-13}$ Although many retrospective and some prospective series reported better (than expected) limb survival in CLI, ${ }^{10,14-16}$ these results have not been substantiated in randomized studies. ${ }^{17-21}$ Later reviews claimed that SCS might be a beneficial therapeutic alternative, particularly in those patients without established gangrene or after the selection of patients using microcirculatory measurements such as transcutaneous oximetry. ${ }^{12,22,23}$ 
The objective of this analysis was to evaluate the impact of demographic, clinical and commonly used circulatory parameters on outcome in a prospectively followed cohort of patients with inoperable CLI. In the largest randomized trial, ${ }^{20}$ a number of predefined factors were analyzed for prognostic value. For calculation of a radiological arterial disease score, the proposed system of the Ad Hoc Committee on Reporting Standards of the Society for Vascular Surgery and the International Society for Cardiovascular Surgery (SVS/ISCVS) was used. ${ }^{24}$ This angiographic scoring system grades the quality of vessels distal to a planned bypass site and calculates an overall runoff score. We applied this system to a lower limb radiological arterial disease score and compared its prognostic ability to other factors.

\section{Methods}

The trial design and procedures have been described in detail elsewhere. ${ }^{20,25}$ Eligible patients had CLI and a meaningful vascular reconstruction was not possible. The arterial anatomy of the lower extremities was assessed by digital subtraction angiography with use of either stepping techniques with a single contrast material bolus or multiple contrast material injections. The need for additional images and selective catheterizations was left to the angiographers performing the examinations. No attempt was made to standardize the angiographic technique. All the centers participating in this study used the same non-reconstructability criteria. These were absence of a suitable autologous vein for distal bypass grafting surgery or the absence of all three crural arteries on a selective angiogram, which was a prerequisite for judgment of the calf and foot arteries. The angiogram should delineate contrast down to the distal foot and the adequacy was validated by an independent vascular surgeon. Inclusion criteria were persistent rest pain for more than 2 weeks or ischemic skin lesions, ankle pressure below $50 \mathrm{mmHg}$ or, in patients with diabetes and incompressible vessels, absent palpable ankle pulses or toe pressure below $30 \mathrm{mmHg}$.

From 17 hospitals in The Netherlands, 120 patients were enrolled from 1991 until 1996. The ethical committees at each center approved the study protocol, and patients gave written informed consent. The treatment strategies SCS in addition to best medical treatment ('SCS-treatment') and best medical treatment alone ('standard treatment') were allocated at random to eligible patients. Standard treatment included analgesics, antithrombotic drugs (aspirin, coumarins), cardiovascular risk factor control, hemorrheologic drugs (such as pen- toxifylline, buflomedil, ketanserin), local wound care and antibiotics, if indicated. There was a list of recommended medications, but no fixed treatment regimen. Chemical lumbar sympathectomy and prostanoids were not excluded, but were used in three patients only. The patients allocated to SCS treatment additionally received an implantable spinal-cord stimulation system. A quadripolar lead (Medtronic, Minneapolis, MN, USA) was placed in the epidural space and connected to an Itrell II pulse generator (Medtronic). Both treatment regimens aimed at adequate pain suppression.

All patients were assessed at 1, 3, 6, 12, and 18 months after randomization and at the end of the study. Between follow-up visits patients came to hospital as often as necessary. Limb survival was defined as the absence of major amputation (amputation above the level of the foot). ${ }^{26}$ The Nottingham Health Profile (NHP) and EuroQol were used to assess quality of life. For further assessment of pain, the McGill Pain Questionnaire was used and the pain-rating index (PRI) was the measure of expressed pain. Analgesic use was recorded and quantified by the medication quantification scale (MQS). During follow-up (at 1, 3, 6, 12, and 18 months), over $90 \%$ of the quality-of-life questionnaires were adequately completed by the patients using reminding letters, if necessary.

\section{Prognostic factors}

A number of predefined factors were collected by the treating physicians of the participating hospitals before randomization. Demographic data included age and sex. Clinical data included diagnosis of diabetes, smoking status, hypertension (systolic blood pressure $\geq 160 \mathrm{mmHg}$ ), history of myocardial infarctions and history of cerebrovascular accidents (CVA) or transient ischemic attacks (TIA). Previous vascular reconstructions were summarized as the number of vascular and endovascular reconstructions at the affected limb. The presence of ischemic skin lesions was categorized to ulcerations or gangrene. A number of patients with ischemic skin lesions had ulceration(s) as well as gangrene. These data were used separately in this analysis. Circulatory measurements included the radiological arterial disease score, the ankle pressure and ankle-brachial index (ABI). The angiograms were re-examined by an independent observer (CHAW) to calculate the radiological arterial disease score, constructed similar to the runoff score of the Ad Hoc Committee on Reporting Standards of the SVS/ISCVS. The integrity of circulation in the affected limb was evaluated on five levels: suprainguinal, infrainguinal, popliteal, infrapopliteal and pedal. A total score was calculated from 1 (full integrity of circulation) to 20 (maximally compromised state) as explained in Table 1. 
Table 1 Calculation of radiological arterial disease score

\begin{tabular}{|c|c|c|c|c|c|}
\hline Arterial segment & Artery & Value & $\times$ weight & Subscore & \\
\hline A. Suprainguinal & $\begin{array}{l}\text { Common iliac } \\
\text { External iliac } \\
\text { Internal iliac } \\
\text { Common femoral }\end{array}$ & $\begin{array}{l}{[0-4]} \\
{[0-4]} \\
{[0-4]} \\
{[0-4]}\end{array}$ & $\begin{array}{l}\times 3 \\
\times 2 \\
\times 1 \\
\times 3\end{array}$ & $\begin{array}{l}(\mathrm{a} 1) \\
(\mathrm{a} 2) \\
(\mathrm{a} 3) \\
(\mathrm{a} 4)>(\mathrm{a} 1+\mathrm{a} 2+\mathrm{a} 3+\mathrm{a} 4) / 9\end{array}$ & A [0-4] \\
\hline B. Infrainguinal & $\begin{array}{l}\text { Superficial femoral } \\
\text { Deep femoral }\end{array}$ & $\begin{array}{l}{[0-4]} \\
{[0-4]}\end{array}$ & $\begin{array}{l}\times 2 \\
\times 1\end{array}$ & $\begin{array}{l}(\mathrm{b} 1) \\
(\mathrm{b} 2)>(\mathrm{b} 1+\mathrm{b} 2) / 3\end{array}$ & B [0-4] \\
\hline $\begin{array}{l}\text { C. Popliteal } \\
\text { D. Infrapopliteal }\end{array}$ & $\begin{array}{l}\text { Popliteal } \\
\text { Anterior tibial } \\
\text { Posterior tibial } \\
\text { Peroneal }\end{array}$ & $\begin{array}{l}{[0-4]} \\
{[0-4]} \\
{[0-4]} \\
{[0-4]}\end{array}$ & $\begin{array}{l}\times 1 \\
\times 1 \\
\times 1\end{array}$ & $\begin{array}{l}\text { (c) } \\
\text { (d1) } \\
(\mathrm{d} 2) \\
(\mathrm{d} 3)>(\mathrm{d} 1+\mathrm{d} 2+\mathrm{d} 3) / 3\end{array}$ & $\begin{array}{l}\text { C [0-4] } \\
\text { D [0-4] }\end{array}$ \\
\hline $\begin{array}{l}\text { E. Pedal arch } \\
\text { 'Base resistance' } \\
\text { Total radiological arterial } \\
\quad \text { disease score }\end{array}$ & Arch & {$[0-3]$} & & $(e)>$ & $\begin{array}{l}E[0-3] \\
1+ \\
A+B+C+D+E+1[1-20]\end{array}$ \\
\hline
\end{tabular}

For four segments (A-D), angiographic disease was scored by weighting of the degree of occlusion in the main arteries. Points assigned as: $0=$ no evidence of disease; $1=$ mild disease (stenosis $<20 \%$ ); $2=$ stenosed $(20-50 \%) ; 3=$ severely stenosed $(51-99 \%) ; 4=$ occluded.

For the pedal arch (E), points were assigned as: $0=$ completely patent arch; $2=$ partially occluded arch; $3=$ completely occluded arch.

A 'base resistance' of 1 is added as arbitrary intrinsic resistance of the normal vascular bed, leading to a radiological arterial disease score ranging from 1 to 20.

We studied not only the prognostic weight of these variables for the risk of amputation, but also their potential influence on the effect of SCS treatment. In a multivariable analysis, the treatment effect was tested as well as the impact of risk factors that emerged from our analysis with $p$-value $<0.20$ or were regarded important in the literature. ${ }^{4,18,27-32}$

All data were recorded on standardized forms and entered in a concurrent database. Analysis of clinical outcome was by intention-to-treat and included all patients who underwent randomization. Patient and limb survival were estimated with the Kaplan-Meier method and compared using logrank tests. In the analysis of limb survival, patients were censored at death. The Cox proportional hazards model was used (1) for analysis with prognostic factors and (2) for analysis of interactions between prognostic factors and treatment. Hazard ratios (HRs) were estimated to quantify the effect of prognostic factors. When the HR was greater than 1 , the risk of amputation was higher with the prognostic factor present than without this factor. In multivariable analyses, we selected prognostic factors with a $p$-value $<0.20$ and the variable indicating SCS treatment. For all hypothesis tests, $p<0.05$ was considered statistically significant.

\section{Results}

A total of 120 patients were included in the study. Sixty patients were randomized to SCS-treatment and 60 patients received standard treatment. The median follow-up was 2 years (range 244-1710 days). Table 2 shows the demographic, clinical and circulatory characteristics. The mean age was 72.6 years, nearly $40 \%$ of the patients were diabetic, and over $60 \%$ had ulcerations or gangrene in addition to rest pain. There was extensive comorbidity and many patients had (multiple) vascular reconstructions on the affected limb. The mean Doppler ankle pressure was $38 \mathrm{mmHg}$ and the mean ABI was 0.25 . The mean radiological arterial disease score was 10.3 .

(Limb) survival data have been presented before. ${ }^{20}$ Mortality was comparable in both treatment groups: at 6 months is was $17 \%$ in both groups, and at 2 years it was $36 \%$ in the SCSgroup vs 37\% in the standard treatment group (log rank, $p=0.96$ ). Limb survival was similar in both treatment groups: at 6 months it was $66 \%$ vs $68 \%$, at 2 years it was $52 \%$ in the SCS-group vs $46 \%$ in the standard treatment group (log-rank, $p=0.47$ ). The general trend in both the SCS and standard treatment groups was toward some improvement of quality of life, with no significant differences between the groups. ${ }^{20}$

The prognostic significance of the studied variables for the risk of amputation is summarized in Table 3. The analysis did not show a significant prognostic influence for age, sex, diabetes, hypertension, history of myocardial infarction or cerebrovascular symptoms, ankle pressure or ABI. Most of the patients $(n=94)$ had previous revascularizations. The amputation outcome between those who had (multiple) previous revascularizations and those who did not was not statistically 
Table 2 Baseline characteristics of study group

\begin{tabular}{llll}
\hline Characteristics & $n=120$ & $\begin{array}{l}n=60 \\
\text { SCS }\end{array}$ & $\begin{array}{l}n=60 \\
\text { Standard }\end{array}$ \\
\hline Male/female & & $33 / 27$ & $37 / 23$ \\
Age (years)* & $70 / 50$ & $72 \pm 11$ \\
Diabetes & $73 \pm 10$ & 22 & 23 \\
$\quad$ Insulin-dependent & 45 & 10 & 9 \\
Current smoking & 19 & 18 & 26 \\
Hypertension & 44 & 35 & 26 \\
CVA or TIA & 61 & 13 & 16 \\
Myocardial infarction & 29 & 23 & 22 \\
Angina pectoris & 45 & 12 & 41 \\
Ischemic skin lesions & 27 & 38 & 23 \\
$\quad$ Gangrene & 79 & 24 & 11 \\
Vascular reconstructions & 47 & 15 & 29 \\
$\quad$ Nil & 26 & 26 & 20 \\
1 or 2 & 55 & 19 & $41 \pm 22$ \\
Ankle systolic pressure (mmHg) & 39 & $35 \pm 25$ & $0.28 \pm 0.13$ \\
Ankle-brachial index* & $38 \pm 24$ & $0.23 \pm 0.16$ & $10.4 \pm 2.6$ \\
Radiological arterial score* & $0.25 \pm 0.15$ & $10.1 \pm 2.9$ &
\end{tabular}

CVA, cerebrovascular accidents; TIA, transient ischemic attacks.

Data given as numbers or ${ }^{*}$ mean \pm SD.

Table 3 Univariate analysis of amputation risk

\begin{tabular}{lll}
\hline Characteristics & HR amputation & $p$-value \\
\hline Male/female & 1.02 & 0.94 \\
Age (years) & 0.99 & 0.93 \\
Diabetes & 1.03 & 0.97 \\
Current smoking & 1.27 & 0.12 \\
Hypertension & 0.98 & 0.86 \\
CVA or TIA & 1.45 & 0.22 \\
Myocardial infarction & 0.97 & 0.91 \\
Angina pectoris & 1.38 & 0.29 \\
Ischemic skin lesions & 2.20 & 0.016 \\
Gangrene & 2.48 & 0.001 \\
Vascular reconstructions & & \\
$\quad$ Nil & & \\
$\quad$ or 2 & $1.10 /$ intervention & 0.18 \\
$\quad$ Ankle systolic pressure & $0.92 / 10$ mmHg & 0.25 \\
$\quad$ (mmHg) & & \\
Ankle-pressure index & 0.87 / 10\% & 0.87 \\
Radiological arterial & $1.11 /$ point & 0.05 \\
$\quad$ score & & \\
\hline
\end{tabular}

CVA, cerebrovascular accidents; TIA, transient ischemic attacks. significant (HR 1.1 per previous revascularization procedure, $p=0.18)$. The HR for smoking was $1.27(p=0.12)$. Patients with ischemic skin lesions (ulcerations or gangrene) had a significantly worse prognosis (i.e. a higher risk of amputation: HR 2.30, $p=0.01$. For the pooled cohort of patients, limb survival at 6 months was $76 \%$ in patients with rest pain and $62 \%$ in patients with ischemic skin lesions; at 2 years it was $65 \%$ and $40 \%$ respectively (logrank, $p<0.01)$. Angiographic abnormality as scored by the radiological arterial disease score was also associated with worse prognosis (HR 1.11 per point increase of the score, $p=0.05$ ). Based on the distribution of the radiological arterial disease score in this cohort of patients, three groups were formed: low score $\leq 8$, intermediate score 9-12 and high score $>12$. Limb survival at 6 months in these groups was $75 \%, 59 \%$ and $53 \%$ and at 2 years was $65 \%, 36 \%$ and $33 \%$ respectively (trend $p=0.03$ ).

A multivariable analysis was performed to estimate the effect of relevant prognostic factors on treatment (predictive effect). The results are summarized in Table 4. Relevant factors were selected from

Table 4 The impact of prognostic factors and treatment effect in the multivariable analysis

\begin{tabular}{lllll}
\hline Factor & HR amputation & $p$-value & HR mortality & $p$-value \\
\hline Presence of gangrene & 2.30 & 0.036 & 1.41 & 0.37 \\
Presence of ulcerations & 2.38 & 0.018 & 1.38 & 0.43 \\
Radiological arterial disease score & 1.17 & 0.003 & 1.10 & 0.14 \\
Current smoking & 1.23 & 0.19 & 1.03 & 0.84 \\
Previous vascular reconstructions & 1.05 & 0.52 & 1.92 & 0.28 \\
SCS-treatment & 0.92 & 0.86 & 1.00 & 0.99 \\
\hline
\end{tabular}

SCS, spinal cord stimulation. 
Table 5 Global estimated risk of major amputation within 6 months in patients categorized according to radiological arterial disease score and absence or presence of ischemic skin lesions

\begin{tabular}{llcl}
\hline $\begin{array}{l}\text { Ischemic skin } \\
\text { lesions }\end{array}$ & \multicolumn{3}{c}{ Radiological arterial disease score } \\
\cline { 2 - 4 } & $4-8$ & $9-12$ & $>12$ \\
\hline No & $15 \%$ & $25 \%$ & $40 \%$ \\
Yes & $25 \%$ & $50 \%$ & $80 \%$ \\
\hline
\end{tabular}

the risk factor analysis combined with the available literature. ${ }^{4,18,27-32}$ Risk factors included were smoking, ischemic skin lesions, the number of previous vascular interventions and radiological arterial disease score. Adjusted for these factors, SCS was no more effective than standard treatment; the HR for the treatment effect (the amputation risk in SCS vs standard treatment) was estimated at 0.92 $(p=0.86)$. We could not identify a subgroup of patients who might specifically be helped by SCS.

Independent risk factors for amputation were: the presence of ischemic skin lesions (HR 2.30, $p=0.036$ for gangrene; HR 2.38, $p=0.018$ for ulcerations) and the radiological arterial disease score (HR 1.17 per point increase of the score, $p=0.003$ ). Global probabilities of amputation within 6 months were estimated for several categories of patients as is shown in Table 5 .

The same factors (i.e. presence of tissue loss, smoking, the number of previous vascular interventions and radiological arterial disease score) were used in a multivariable analysis to estimate the influence on mortality risk. This analysis did not show significant associations of these factors with mortality (Table 4).

\section{Discussion}

In this cohort of patients with non-reconstructable CLI, the presence of ischemic skin lesions and a higher radiological arterial disease score, which can be easily calculated for each patient undergoing angiography, were significantly associated with amputation risk. Baseline risk estimation is important for the evaluation of treatment outcome in patients with peripheral arterial disease..$^{33,34}$

Definition of the patient populations in studies assessing the efficacy of therapies of peripheral arterial disease is often complex and previously defined criteria and estimation of baseline risk have been disputed. ${ }^{26,27}$ Comparison of studies is therefore difficult. Uniform reporting information remains the best method for allowing comparisons of studies involving differing revascularization techniques or medical management. Such data would provide more information on decisions about treatment in relation to baseline risk probabilities.

Limb-threatening ischemia as characterized by rest pain or ischemic skin lesions usually signals the need for evaluation of revascularization options and therefore the location and severity of stenoses and patency of runoff vessels must be precisely assessed. Several imaging techniques are available to visualize the macroscopic vessels (digital subtraction angiography, MR angiography, ultrasonography). ${ }^{35,36}$ Runoff scores for segments of the arterial system have been specifically used to describe changes in peripheral circulatory patency after revascularization techniques. The original intention was to use these scores for research and not for clinical purposes. ${ }^{24}$ However, imaging scores can also be used as a baseline characteristic for evaluation of conservative treatments. In CLI, it is often very difficult to decide for amputation. Although statistics can never replace clinical judgment, quantification of the burden of lower extremity atherosclerosis may be a valuable objective factor in this decision analysis.

If meaningful revascularization strategies are lacking, therapeutic options are limited. The evaluation of non-surgical management as in spinal cord stimulation, vasoactive drugs or angiogenesis therapies underscores the need to develop and validate methods of assessing the severity or extent of PVD. In this study, we tested a simple scoring system that uses angiography to estimate the extent of macroscopic arterial disease. To be useful, such a scoring system must be reproducible. High correlation coefficients for inter- and intraobserver variability were reported by Crawford. ${ }^{37}$

Limitations of the current analysis include interpretation issues and the studied patient group. The interpretation of angiograms remains subjective. The reader visually estimated the degree of stenosis using the pre-randomization angiography series from the participating hospitals. The interpretation of the transition point from the SFA to popliteal artery, collaterals, bypass grafts or variant anatomy remains rather arbitrary. In the calculation of the radiological arterial disease score, as presented in Table 1, only the metatarsal arch is scored in the foot. The assessment may be refined if the lateral and medial plantar branch and the dorsalis pedis branch were added to this score. The classification and generalization performance of the scoring system may be improved by better rules for scoring or by the use of computer-aided learning systems. The conversion factors used to translate angiographic findings into the score estimates (especially in multilevel disease) can be revised in such systems as well.

Despite these limitations, the radiological arterial disease score can be easily calculated for each 
patient with CLI undergoing angiography. Further evaluation in other prospectively followed cohorts should refine its prognostic value for the broader group of patients with occlusive peripheral vascular disease.

Calculation of the radiological arterial disease score combined with the presence or absence of ischemic skin lesions can be used to estimate the probability of amputation in patients with critical lower limb ischemia. This may be relevant to the management of patients with multi-level disease and poor outflow in order to opt for risky revascularization, primary amputation or medical therapy. Moreover, estimation of baseline amputation risk is important for evaluation of (medical) treatments.

\section{Acknowledgements}

This study was financed by the Dutch Fund for Investigative Medicine (OG90053) of the Health Care Insurance Council, Amstelveen, The Netherlands.

We are indebted to all members of the ESES study group: (University Hospital Groningen) JJAM van den Dungen, MJ Staal; (Medisch Spectrum Twente, Enschede) RJ van Det, HE van de Aa; (De Weezenlanden Hospital, Zwolle) EA Kole; (St Antonius Hospital, Nieuwegein) FL Moll, AL Liem; (Medisch Centrum Alkmaar) HA van Dijk, PJ Theuvenet; (Hospital Leyenburg, Den Haag) JC Sier, N Lambooy; (St Clara Hospital, Rotterdam) TI Yo, G Kazemier; (St Franciscus Gasthuis, Rotterdam) CHA Wittens; (University Hospital Rotterdam-Dijkzigt) NAJJ duBois, AI Veeger, H van Urk; (Catharina Hospital, Eindhoven) J Buth; (De Wever Hospital, Heerlen) ECM Bollen, J Lens, GH Spincemaille, W Hollander; (Maasland Hospital, Sittard) AGM Hoofwijk; (University Hospital Maastricht) JHM Tordoir; (Lievensberg, Bergen op Zoom) THA Bikkers; (Deventer Hospitals) D van Lent, PJ van Elk; (Academic Medical Center, Amsterdam) MJHM Jacobs, DTh Ubbink; (Hospital St Jansdal, Harderwijk) AC van der Ham.

We thank Scarlet van Belle for data management and secretarial assistance.

\section{References}

1 TASC. Management of peripheral arterial disease (PAD). TransAtlantic Inter-Society Consensus (TASC). Section D: chronic critical limb ischaemia. Eur J Vasc Endovasc Surg 2000; 19(suppl A): S144-S243.

2 Sayers RD, Thompson MM, London NJM, Varty K, Naylor AR, Budd JS, et al. Selection of patients with criti- cal limb ischaemia for femorodistal vein bypass. Eur $J$ Vasc Surg 1993; 7: 291-297.

3 Troeng T, Bergqvist D, Janson L. Incidence and causes of adverse outcomes of operation for chronic ischaemia of the leg. Eur J Surg 1994; 160: 17-25.

4 Second European Consensus Document on chronic critical leg ischemia. Circulation 1991; 84(Suppl. 4): IV1-IV26.

5 Rivers SP, Veith FJ, Ascer E, Gupta SK. Successful conservative therapy of severe limb-threatening ischemia: the value of nonsympathectomy. Surgery 1986; 99: 759-762.

6 Dormandy J, Mahir M, Ascady G, Balsano F, Leeuw PD, Blombery $\mathrm{P}$, et al. Fate of the patient with chronic leg ischemia. J Cardiovasc Surg 1989; 30: 50-57.

7 Taylor LM, Hamre D, Dalman RL, Porter JM. Limb salvage versus amputation for critical ischemia, the role of vascular surgery. Arch Surg 1991; 126: 1251-1258.

8 Troeng T, Bergqvist D, Janzon L, Jendteg S, Lindgren B. The choice of strategy in the treatment of critical leg ischaemia. Theor Surg 1993; 8: 115-121.

9 Marston WA, Davies SW, Armstrong B, Farber MA, Mendes RC, Fulton JJ, et al. Natural history of limbs with arterial insufficiency and chronic ulceration treated without revascularization. J Vasc Surg 2006; 44: 108-114.

10 Horsch S, Schulte S, Hess S. Spinal cord stimulation in the treatment of peripheral vascular disease: results of a singlecenter study of 258 patients. Angiology 2004; 55: 111-118.

11 Gersbach PA, Argitis V, Gardaz JP, von Segesser LK, Haesler E. Late outcome of spinal cord stimulation for unreconstructable and limb-threatening lower limb ischemia. Eur J Vasc Endovasc Surg 2007; 33: 717-724.

12 Pedrini L, Magnoni F. Spinal cord stimulation for lower limb ischemic pain treatment. Interact Cardiovasc Thorac Surg 2007; 6: 495-500.

13 Ubbink DT, Vermeulen H. Spinal cord stimulation for critical leg ischemia: a review of effectiveness and optimal patient selection. J Pain Symptom Manage 2006; 31 (Suppl. 4): S30-S35.

14 Jivegard L, Augustinsson L, Carlsson C, Holm J. Longterm results by epidural spinal electrical stimulation (ESES) in patients with inoperable severe lower limb ischemia. Eur J Vasc Surg 1987; 1: 345-349.

15 Spincemaille GH, de Vet HC, Ubbink DT, Jacobs MJ. The results of spinal cord stimulation in critical limb ischaemia: a review. Eur J Vasc Endovasc Surg 2001; 21: 99-105.

16 Amann W, Berg P, Gersbach P, Gamain J, Raphael JH, Ubbink DT. Spinal cord stimulation in the treatment of non-reconstructable stable critical leg ischaemia: results of the European Peripheral Vascular Disease Outcome Study (SCS-EPOS). Eur J Vasc Endovasc Surg 2003; 26: 280-286.

17 Suy R, Gybels J, Van Damme H, Martin D, Van Maele R, Delaporte C. Spinal cord stimulation for ischemic rest pain. The Belgian randomized study. In: Horsch S, Claeys L, (eds). Spinal cord stimulation - an innovative method for the treatment of PVD. Steinkopff Verlag: Darmstadt/ Springer International, 1994, 197-202.

18 Jivegard LE, Augustinsson LE, Holm J, Risberg B, Ortenwall P. Effects of spinal cord stimulation (SCS) in patients with inoperable severe lower limb ischaemia: a prospective randomised controlled study. Eur J Vasc Endovasc Surg 1995; 9: 421-425.

19 Claeys LG, Horsch S. Transcutaneous oxygen pressure as predictive parameter for ulcer healing in endstage vascular 
patients treated with spinal cord stimulation. Int Angiol 1996; 15: 344-349.

20 Klomp HM, Spincemaille GH, Steyerberg EW, Habbema JD, van Urk H. Spinal-cord stimulation in critical limb ischaemia: a randomised trial. ESES Study Group. Lancet 1999; 353: 1040-1044.

21 Spincemaille GH, Klomp HM, Steyerberg EW, Habbema JDF. Spinal cord stimulation in patients with critical limb ischemia: a preliminary evaluation of a multicentre trial. Acta Chir Austriaca 2000; 32: 49-51.

22 Erdek MA, Staats PS. Spinal cord stimulation for angina pectoris and peripheral vascular disease. Anesthesiol Clin North Am 2003; 21: 797-804.

23 Claeys LG, Berg W, Jonas S. Spinal cord stimulation in the treatment of chronic critical limb ischemia. Acta Neurochir 2007; 97(Suppl.): 259-265.

24 Rutherford RB, Baker JD, Ernst C, Johnston KW, Porter JM, Ahn S, et al. Recommended standards for reports dealing with lower extremity ischemia: revised version. J Vasc Surg 1997; 26: $517-538$.

25 Klomp HM, Spincemaille GH, Steyerberg EW, Berger MY, Habbema JD, van Urk H. Design issues of a randomised controlled clinical trial on spinal cord stimulation in critical limb ischaemia. ESES Study Group. Eur J Vasc Endovasc Surg 1995; 10: 478-485.

26 Norgren L, Hiatt WR, Dormandy JA, Nehler MR, Harris KA, Fowkes FG, et al. Inter-Society Consensus for the Management of Peripheral Arterial Disease (TASC II). Eur J Vasc Endovasc Surg 2007; 33(Suppl. 1): S1-S75.

27 Thompson MM, Sayers RD, Varty K, Reid A, London NJ, Bell PR. Chronic critical leg ischaemia must be redefined. Eur J Vasc Surg 1993; 7: 420-426.

28 Lepantalo M, Matzke S. Outcome of unreconstructed chronic critical leg ischaemia. Eur J Vasc Endovasc Surg 1996; 11: 153-157.
29 Jensen LP. Intermittent claudication. Conservative treatment, endovascular repair or open surgery for femoropopliteal disease. Ann Chir Gynaecol 1998; 87: 137-140.

30 Gupta SK, Veith FJ, Ascer E, Flores SA, Gliedman ML. Cost factors in limb-threatening ischaemia due to infrainguinal arteriosclerosis. Eur J Vasc Surg 1988; 2: 151-154.

31 Panneton J, Gloviczki P, Bower T, Rhodes J, Canton L, Toomey B. Pedal bypass for limb salvage: impact of diabetes on long-term outcome. Ann Vasc Surg 2000; 14: 640647.

32 Niekerk LV, Stewart C, Jain A. Major lower limb amputation following failed infrainguinal vascular bypass surgery: a prospective study on amputation levels and stump complications. Prosthet Orthot Int 2001; 25: 238-245.

33 Taylor SM, Kalbaugh CA, Blackhurst DW, Cass AL, Trent EA, Langan 3rd EM, et al. Determinants of functional outcome after revascularization for critical limb ischemia: an analysis of 1000 consecutive vascular interventions. J Vasc Surg 2006; 44: 747-755 discussion 755-756.

34 Toursarkissian B, D’Ayala M, Stefanidis D, Shireman PK, Harrison A, Schoolfield J, et al. Angiographic scoring of vascular occlusive disease in the diabetic foot: relevance to bypass graft patency and limb salvage. J Vasc Surg 2002; 35: 494-500.

35 Lapeyre M, Kobeiter H, Desgranges P, Rahmouni A, Becquemin JP, Luciani A. Assessment of critical limb ischemia in patients with diabetes: comparison of MR angiography and digital subtraction angiography. AJR Am J Roentgenol 2005; 185: 1641-1650.

36 Meissner OA, Rieger J, Weber C, Siebert U, Steckmeier B, Reiser MF, et al. Critical limb ischemia: hybrid MR angiography compared with DSA. Radiology 2005; 235: 308-318.

37 Crawford ST, Olsen RV, Pilgram TK, Duncan JR. Validation of an angiographic method for estimating resting blood flow to distal tissue beds in the lower extremities. $J$ Vasc Interv Radiol 2003; 14: 555-565. 